\title{
Green and Quick Extraction of Stable Biophenol-Rich Red Extracts from Grape Processing Waste
}

\author{
Marzia Sciortino, ${ }^{1}$ Giuseppe Avellone, ${ }^{1 *}$ Antonino Scurria,,${ }^{2}$ Luca Bertoli, ${ }^{3}$ Diego Carnaroglio, ${ }^{3}$ David \\ Bongiorno, ${ }^{1}$ Mario Pagliaro, ${ }^{2}$ Rosaria Ciriminna ${ }^{2 *}$ \\ ${ }^{1}$ Dipartimento di Scienze e Tecnologie Biologiche Chimiche e Farmaceutiche, Università di Palermo, via Archirafi 32, 90123 Palermo, Italy \\ ${ }^{2}$ Istituto per lo Studio dei Materiali Nanostrutturati, CNR, via U. La Malfa 153, 90146 Palermo, Italy \\ ${ }^{3}$ Milestone, via Fabenefratelli, 1-5, 24010 Sorisole, Bergamo, Italy
}

\section{ARTICLE INFO}

\section{Keywords:}

Grape processing waste

Polyphenols

Green extraction

Microwave-hydrodiffusion and gravity

Enocyanin

Resveratrol

Flavonoids

Anthocyanins

Wine pomace
ABSTRACT

The extraction of grape processing waste (wine pomace) via microwave-hydrodiffusion and gravity (MHG) from three different cultivars grown in Sicily (Syrah, Perricone and Nero d'Avola) rapidly affords aqueous extracts highly concentrated in valued biophenols including flavonoids, anthocyanins and phenolic acids. The method does not employ organic solvent, acid or base and does not require grinding or freeze drying of the wine pomace nor separation of the grape skins from seeds and stem. All the extracts have a pronounced stability as shown by their red-violet color fully retained after storage for more than a year (15 months) in freezer under air. Concentrations of phenolics up to $2000 \mathrm{ppm}$ were detected in the aged extracts of Sicily's local cultivar Perricone, which also has the highest content of flavonoids. These findings provide a simple and economically viable extraction route to biophenol-rich red extracts that can be used as food colorants as well as to formulate nutraceutical, cosmetic and personal care products starting from an agricultural by-product available in $>10$ million tonne yearly amount.

\section{Introduction}

Available worldwide in over 10 million tonne/year amount (and counting), grape (Vitis vinifera L.) processing waste (wine or grape pomace) has long been identified as a convenient source of valued dietary fiber and phenolic compounds. ${ }^{1}$ In winemaking after grape pressing, about $60-70 \%$ of grape phenolic compounds remain in the pomace. $^{2}$ Red wine pomace, in particular, has become a source of resveratrol used in many cosmetic products, even though many other valued phenolic compounds having health-beneficial properties including anti-inflammatory, antimicrobial, anticancer and antithrombotic activity can be sourced from this biological resource. $^{3}$ Alone, $\$ 59$ million in 2019 global resveratrol market is expected to reach $\$ 80$ million by 2025 , growing at a compound annual growth rate of $7.7 \%{ }^{4}$

The industrial extraction of grape polyphenols, in general, makes use of conventional solid-liquid extraction via maceration or Soxhlet extraction with polar organic solvents such as ethanol or acetone. In the last two decades (20002019), numerous alternative grape phenolics extraction routes -- including acoustic cavitation, microwave-assisted extraction, pressurized solvent, and supercritical fluid extraction -- have been demonstrated, ${ }^{5}$ though a few have been industrialized.

Holding large industrial potential, ${ }^{6}$ microwave-assisted extraction (MAE) of grape polyphenols from grape pomace has been widely explored since the early 2000s. After comprehensive optimization research, scholars in Croatia in 2016 discovered the optimal conditions for the MAE of phenolic compounds and anthocyanins from grape skin pomace: eight consecutive extraction cycles, each lasting 16 min, using $100 \%$ methanol added with $1 \% \mathrm{HCl}$ as solvent at 60 ${ }^{\circ} \mathrm{C}$ for polyphenols; and five consecutive extraction cycles, each lasting $16 \mathrm{~min}$, using $92 \%$ methanol solvent added with $0.6 \% \mathrm{HCl}$ at $45{ }^{\circ} \mathrm{C}$ for anthocyanins. ${ }^{7,8}$

Added as food coloring to several food products including beverages (soft drinks, wine, and liqueurs), jams, candies, ice creams, yogurts, and desserts, enocyanin is the name of the water-soluble grape skin extract widely used as food colorant (labelled E163 in EU countries). ${ }^{9}$ Its pronounced solubility and high colouring strength, allows to add very small amount of enocyanin (usually at concentrations between 20 and $60 \mathrm{ppm}$ ) causing no change in taste or smell of the treated products. ${ }^{10}$

Commercially extracted since 1879 (in Italy) first using ethanol, and subsequently for over a century in numerous countries via maceration of wine pomace in a $0.2 \%$ sulhur dioxide aqueous solution (to protect the pigment from oxidation and microbial spoilage), ${ }^{11}$ enyocianin is an important part of the anthocyanin global market currently growing at fast pace (forecasted to $\$ 750$ million in 2026). ${ }^{12}$

Now we report the extraction of grape processing waste (wine pomace) via microwave-hydrodiffusion and gravity (MHG) from three different grape cultivars grown in Sicily (Syrah, Perricone and Nero d'Avola). Affording stable aqueous red extracts rich in grape flavonoids, phenolic acids and anthocyanins, the method does not require grinding or freeze drying of the wine pomace nor separation from seeds and stem. No organic solvent or acid is used throughout the 
process, eliminating the need for hazardous or toxic substances to extract the valued biophenols from wine pomace.

All the extracts have a pronounced stability as shown by their red-violet color fully retained after storage for more than a year (15 months) in freezer under normal atmosphere. Concentrations of phenolics up to $2000 \mathrm{ppm}$ were detected in the aged extracts of Sicily's local cultivar Perricone, which also has the highest content of flavonoids.

\section{Materials and Methods}

Wine pomaces from grapes organically harvested in September 2019 originating from Sicily's vine-growing region of Monreale were kindly provided from Aziende Agricole Biologiche Tamburello (Monreale, Italy). Pomace samples including skins, seeds, residual pulp and stems were processed as such, with no prior treatment before the MHG extraction. An Ethos X microwave extractor (Milestone, Sorisole, Italy) was used for the extraction of water-soluble compounds from grape pomace samples under the conditions of Table 1.

Table 1. Perricone, Syrah, and Nero d'Avola wine pomace amounts undergoing MHG extraction after soaking in water

\begin{tabular}{|l|l|l|}
\hline Cultivar & $\begin{array}{l}\text { Wine pomace } \\
\text { amount }(\mathrm{g})\end{array}$ & Water $(\mathrm{mL})$ \\
\hline Syrah & 550 & 200 \\
\hline Nero d'Avola & 560 & 200 \\
\hline Perricone & 260 & 200 \\
\hline
\end{tabular}

Each grape processing waste material was soaked in 200 $\mathrm{mL}$ water. Pomace readily adsorbed most of the added water. The resulting hydrated pomace was transferred to the $2 \mathrm{~L}$ vessel of the microwave extractor. The aqueous extract generated by microwave irradiation by hydrodiffusion, falls under the action of gravity through a spiral condenser outside the microwave cavity (Figure 1). A $1 \mathrm{~kW}$ chiller was used to condense the aqueous extract. The extraction was digitally followed via the EasyControl software (Milestone, Sorisole, Italy). Extraction was carried out under the conditions of Table 2 for which a brief step $(5 \mathrm{~min})$ using higher power $(500 \mathrm{~W})$ was followed by $50 \mathrm{~min}$ extraction under relatively low (200 W) microwave irradiation power.

Table 2. Extraction program in the MHG extracttion of Perricone, Syrah, and Nero d'Avola wine pomaces

\begin{tabular}{|l|l|l|}
\hline Step & Time $($ min) & Power $(\mathbf{W})$ \\
\hline 1 & 5 & 500 \\
\hline 2 & 50 & 200 \\
\hline
\end{tabular}

Aqueous extracts deeply colored in red-violet were obtained for each wine pomace. The extracts were poured in $60 \mathrm{~mL}$ plastic vials, capped and stored as such in a freezer for 15 months. No nitrogen or other inert gas was inserted in the vials to remove air. After 15 months, a vial of each extract was left at room temperature for several hours after which the redviolet $60 \mathrm{~mL}$ liquid thereby recovered underwent freeze-drying of each aqueous extract using a FreeZone 4.5 (Labconco, Kansas City, MO, USA) freeze-dryer.

Eventually, $111 \mathrm{mg}$ of Nero d'Avola, $110 \mathrm{mg}$ of Syrah and $107 \mathrm{mg}$ of Perricone powder extracts were recovered. Each powder was added to a $15 \mathrm{~mL}$ Falcon conical centrifuge tube.
A $3 \mathrm{~mL}$ aliquot of HPLC grade $\mathrm{MeOH}$ (Sigma Aldrich, St. Louis, MO, USA) was added to each Falcon.

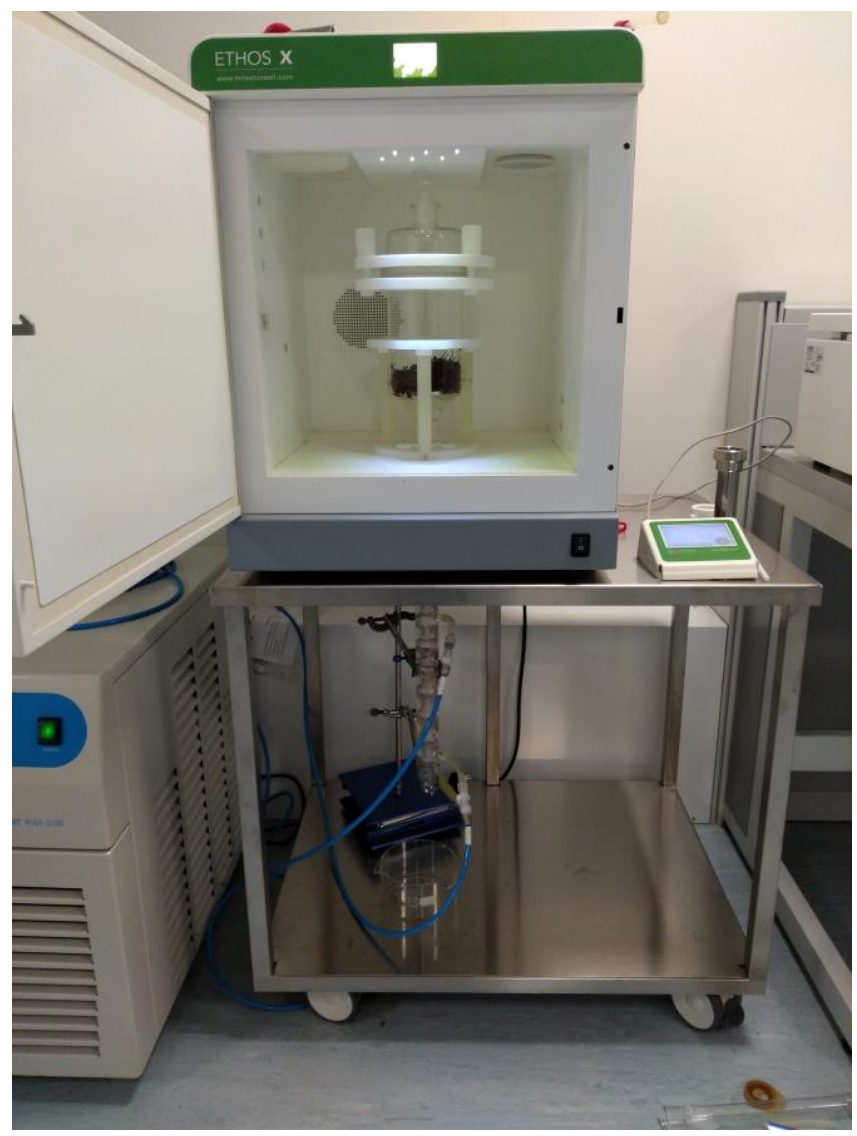

Figura 1. A $2 \mathrm{~L}$ vessel was used along with a $1 \mathrm{~kW}$ chiller to cool down the flavour condensation module at the bottom of the microwave hydrodiffusion and gravity (MHG) extractor.

The ultrasound-assisted extraction of phenolic compounds from each powder was carried out at room temperature using a Transsonic $460 \mathrm{H}$ ultrasonic bath (Elma Hans Schmidbauer, Singen, Germany) operated for $15 \mathrm{~min}$ at $35 \mathrm{kHz}$ ultrasonic frequency. After sonication, each tube underwent centrifugation at 5,000 rpm for 5 min using a Thermo Fisher Scientific SL 16 centrifuge (Thermo Fisher Scientific, Waltham, MA, USA). The supernatant was recovered and 3 $\mathrm{mL}$ of fresh $\mathrm{MeOH}$ were added to the solid residue. This $\mathrm{MeOH}$ aliquot was recovered, followed by addition of another $3 \mathrm{~mL} \mathrm{MeOH}$. Overall, the $9 \mathrm{~mL}$ methanolic extract was eventually reduced to $1.6 \mathrm{~mL}$ via evaporation under reduced pressure.

Only the red-colored Nero d'Avola methanolic extract did not show turbidity. The other two extracts displayed some turbidity and were colored in orange-dark red. The supernatant of each sample was filtered and transferred to glass vials for the high performance liquid chromatography-mass spectrometry (HPLC-MS) analyses conducted using a Alliance e2695 (Waters, Milford, MA, USA) HPLC system equipped with autosampler, degasser and column heater coupled with a Q-Tof Premier (Waters, Milford, MA, USA) quadrupole timeof-flight mass spectrometer.

Compounds in each sample were separated by a Thermo Fisher Scientific Hypersil GOLD HPLC column $(50 \times 2.1 \mathrm{~mm}$ I.D., Thermo Fisher Scientific, Waltham, MA, USA) kept at 20 ${ }^{\circ} \mathrm{C}$ injecting each time a $5 \mu \mathrm{L}$ sample. All samples were 
injected in duplicate using a thermostated autosampler kept at $4{ }^{\circ} \mathrm{C}$. The HPLC eluent was a mixture of $0.1 \mathrm{wt} \%$ aqueous formic acid and $0.1 \mathrm{wt} \%$ formic acid in $\mathrm{MeOH}$ flown at 0.25 $\mathrm{mL} / \mathrm{min}$ rate.

Elution started with $95 \%$ aqueous formic acid and 5\% methanol formic acid, isocratic for $1 \mathrm{~min}$. In the subsequent 14 min the solvent becomes $100 \% \mathrm{MeOH}$, remaining isocratic for the subsequent $5 \mathrm{~min}$ (from $\min 15$ to $\min 20$ ). After $30 \mathrm{~s}$, the eluting solvent mixture was reverted to $95 \%$ aqueous formic acid and 5\% methanolic formic acid, and kept as such for another $30 \mathrm{~s}$. The whole run lasted $21 \mathrm{~min}$. Every sample was injected twice. The concentration values reported in Table 4 are the arithmetic mean of the values measured in each run.

Quantification of quercetin, resveratrol and gallic acid used as standards authentic samples of HPLC purity purchased from a chemical supplier (Sigma Aldrich, St. Louis, MO, USA). For the remaining compounds, we used the calibration curve of quercetin for the detection of flavonoids and anthocyanis, and the calibration curve of resveratrol for the assessment of other biophenols.

The MS experiments were performed on the aforementioned Q-Tof Premier mass spectrometer using dynamic range enhancement (DRE) as acquisition mode that avoids MCP saturation while keeping a fairly good sensitivity. This allows to correctly quantify abundant as well as trace level compounds, providing results suitable for statistical analysis. Atmospheric pressure chemical ionization (APCI) in negative mode was used under the following conditions: capillary, $2.0 \mathrm{kV}$; extraction cone, $2.0 \mathrm{~V}$; ion guide, $2.0 \mathrm{~V}$; source temperature $80{ }^{\circ} \mathrm{C}$, cone gas, $\mathrm{N}_{2}$, flow $35 \mathrm{~L} \mathrm{~h}^{-1}$; desolvation gas, $\mathrm{N}_{2}$, flow $300 \mathrm{~L} \mathrm{~h}^{-1}$.

The following compounds were researched in each wine pomace analyzed: quercetin, naringin, sinapinic acid, rutin, quercetin-3-glucuronide, naringenin, hesperidin, hesperetin, eriodictyol, eriocitrin, diosmin, caftaric acid, petunidin-3-O(6' '-acetylglucoside), cyanidin-3-O-glucoside, malvidin-3-Opentoside, peonidin-3-O-glucoside, resveratrol, resveratrol dimer, resveratrol trimer, resveratrol tetramer, resveratrol glucoside, kaempferol, kaempferol-7- $O$-hexuronide, quercetin3-O-(6"'-O-malonyl-glucoside), quercetin-3-O-hexuronide, kaempferol-3-O-glucoside, quercetin-3-O-galactoside, myricetin-3-O-glucoside, myricetin, epicatechin-3-Ocoumarate, epicatechin-3-O-vanillate, epigallocatechin, procyanidin $\mathrm{B} 3$, catechin, procyanidin $\mathrm{B} 2$, procyanidin $\mathrm{C} 1$, procyanidin dimer B type, gallocatechin, ferulic acid, ellagic acid, prodelphinidin $\mathrm{B}$, epicatechin-3-glucoside, caffeic acid methyl ester, 3-O-caffeoyl-5-O- - -coumaroylquinic acid, $p$ coumaric acid, gallic acid ethyl ester, vanillic acid, caffeic acid, $p$-hydroxybenzoic acid, gallic acid.

\section{Results and Discussion}

The system was able to reliably follow the extraction heating program with a full traceability of time, power and temperature. Under the conditions applied (Table 2), the temperature in the extraction vessel rapidly reached $78^{\circ} \mathrm{C}$ and subsequently remained constant. The overall extraction lasted each time $55 \mathrm{~min}$, after which an aqueous extract deeply colored in red (Figure 2, top) was readily isolated for all three cultivar wine pomaces leaving the extracted wine pomace (Figure 2, bottom) ready for composting.

Results in Table 3 show an exceptionally high content of polyphenols for the Perricone wine pomace, and a very high amount of the same compounds in the Syrah wine pomace.
Only the pomace residual of Nero d'Avola winemaking process had a polyphenol content $<1000 \mathrm{mg} / \mathrm{kg}$. For simplicity. Table 3 and Table 4 list anthocyanins alone (i.e., not amid flavonoids) although anthocyanins are flavonoids with a positive charge at the oxygen atom of the C-ring of basic flavonoid structure.
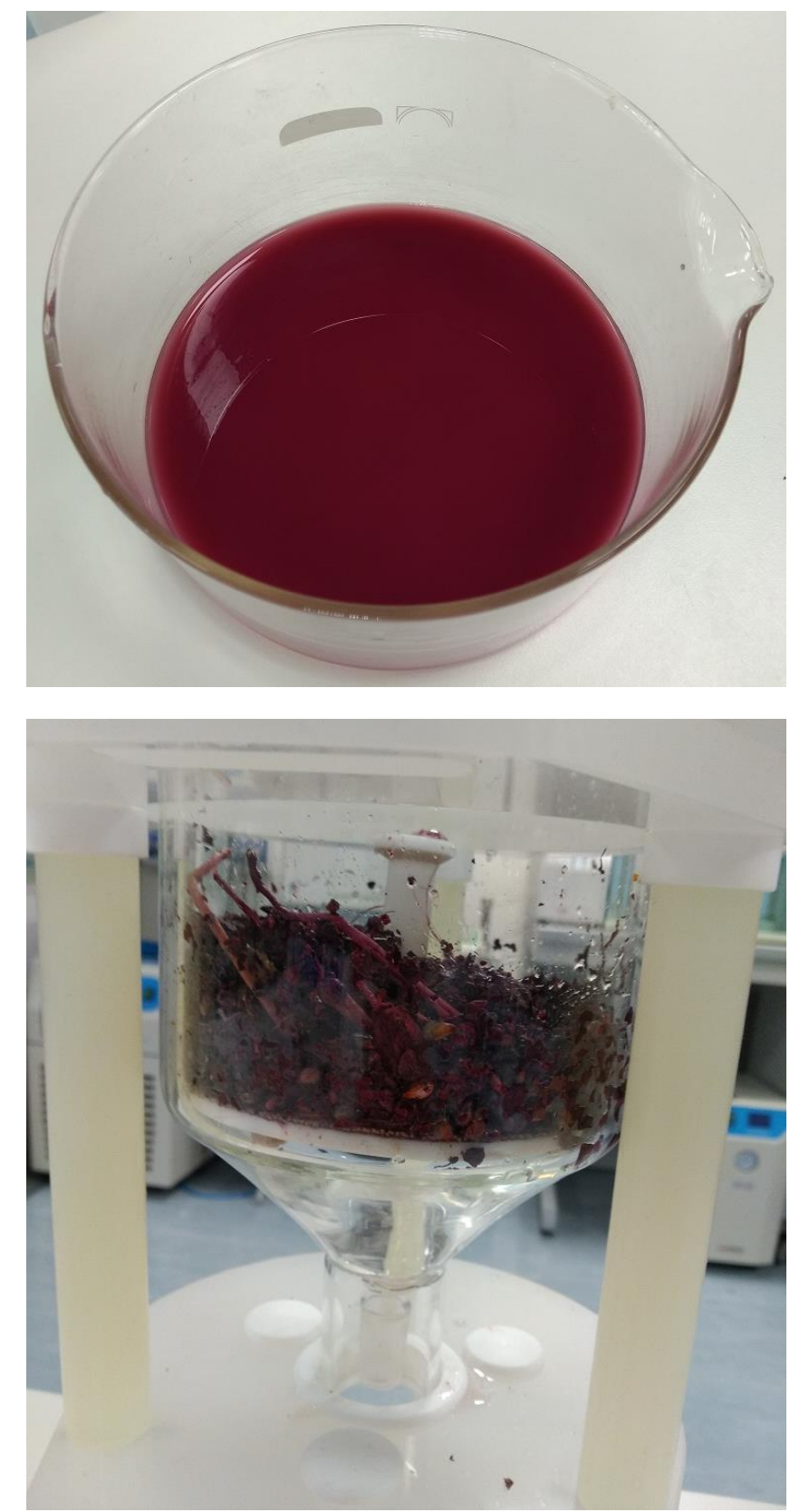

Figura 2. Syrah aqueous extract collected after wine pomace extraction via microwave hydrodiffusion and gravity (top) and the residual wine pomace after extraction (bottom).

Results in Table 4 show that cyanidin-3-O-glucoside was the dominant anthocyanin found in the acqueous extract under the applied MHG extraction conditions, in amount (ca. 25 $\mathrm{mg} / \mathrm{kg}$ ) almost independent of the cultivar.

This outcome is in agreement with literature data for which the dominant anthocyanin in the Perricone wine and grape is the malvidin-3-O-glucoside, followed by substituted anthocyanins and particularly by petunidin, peonidin, delphinidin 3-O-glucosides, ${ }^{13}$ because winemaking techniques limit the amount of anthocyanin that can be extracted from the berry skins to less than $7 \%$ of cyanidin-3-O-glucoside. ${ }^{14}$ 
Table 3. Total polyphenol content and relative amounts of flavonoids, phenolic acids and anthocyanins in the MHG extracts of Perricone, Syrah, and Nero d'Avola wine pomaces.

\begin{tabular}{llll}
\hline Compounds & $\begin{array}{l}\text { Perricone } \\
(\mathrm{mg} / \mathrm{kg})\end{array}$ & $\begin{array}{l}\text { Syrah } \\
(\mathrm{mg} / \mathrm{kg})\end{array}$ & $\begin{array}{l}\text { Nero d'Avola } \\
(\mathrm{mg} / \mathrm{kg})\end{array}$ \\
\hline $\begin{array}{l}\text { Total } \\
\text { polyphenols }\end{array}$ & 2049.12 & 1469.55 & 890.76 \\
Flavonoids & $29.63 \%$ & $32.77 \%$ & $39.19 \%$ \\
Phenols & $69.17 \%$ & $65.66 \%$ & $57.60 \%$ \\
Anthocyanins & $1.20 \%$ & $1.57 \%$ & $3.21 \%$ \\
\hline
\end{tabular}

Table 4 lists the flavonoid and other phenolic compounds found using the highly sensitive HPLC-MS technique employed for the analysis.

Amid phenolic acids, gallic acid, which is known to be along with catechin, and epicatechin particularly abundant in the seeds of red and whote grape varieties, ${ }^{15-16}$ was found in very high amount $(519 \mathrm{mg} / \mathrm{kg})$ in the Perricone wine pomace extract, along with gallic acid ethyl ester $(435 \mathrm{mg} / \mathrm{kg})$ and syringic acid $(350 \mathrm{mg} / \mathrm{kg})$, another hydroxybenzoic acid typical (with $p$-hydroxybenzoic acid) of wines and grapes.

While gallic acid is found in the grape itself, it is also released following the hydrolysis of the gallic acid esters of flavan-3-ols, ${ }^{17}$ whereas the large amounts of gallic acid ethyl esters likely formed thanks to the acid-catalyzed esterification reaction of gallic acid and ethanol formed during sugar fermentation occurring also in the wine pomace. These results are partly in agreement with the analyses of the red wine pomace of Cabernet Sauvignon pomace and Feteasca Neagra cultivars also finding abundant amounts of gallic and syringic acid. ${ }^{17}$

Resveratrol isomers were found in all three cultivar wine pomaces. Again, resveratrol, present in all the natural forms, was particularly abundant in the Perricone cultivar wine pomace (free, dimer, trimer and tetramer together $>73 \mathrm{mg} / \mathrm{kg}$ ) and also in the Nero d'Avola wine pomace (free, dimer, trimer and tetramer together $>42 \mathrm{mg} / \mathrm{kg}$ ). They Syrah processing waste extract had the lowest resveratrol content $(<20 \mathrm{mg} / \mathrm{kg})$. For comparison, the amount of resveratrol extracted by researchers in Italy with $\mathrm{MeOH} / \mathrm{EtOH}$ from freeze-dried grape skins and grape pomace of Nero d'Avola was 27.5 and 6.00 $\mathrm{mg} / \mathrm{kg}$, respectively. ${ }^{18}$

In agreement with previous findings concerning the wine pomace of another Sicilian red grape cultivar (Nerello Mascalese),${ }^{19}$ quercetin (and its glycoside derivatives quercetin 3-O-glucuronide and quercetin-3-O-galactoside) was the dominant flavonoid detected in the three grape cultivar lyophilized aqueous extracts, with the Perricone extract containing almost $180 \mathrm{mg} / \mathrm{kg}$ of this dietary flavonol known for its powerful antioxidant, antihypertensive, antiinflammatory, antiobesity, and antiatherosclerotic activities. ${ }^{20}$

Kaempferol, another powerful bioactive flavonoid with a broad range of physiological (anti-cancer, antioxidant and antiinflammatory) activities, ${ }^{21}$ was also abundant in all three cultivar aqueous MHG extracts. The three forms found, including kaempferol-7-O-glucuronide and kaempferol-3-Oglucoside, approach $100 \mathrm{mg} / \mathrm{kg}$ in the case of the Perricone extract, followed by ca. $70 \mathrm{mg} / \mathrm{kg}$ for both the Syrah and the Nero d'Avola extracts.
Table 4. Flavonoids, phenolic acids and anthocyanins in the MHG aqueous extracts of Perricone, Syrah, and Nero d'Avola red wine pomaces.

\begin{tabular}{|c|c|c|c|}
\hline Phenolic class & $\begin{array}{l}\text { Perricone } \\
(\mathrm{mg} / \mathrm{kg})\end{array}$ & $\begin{array}{l}\text { Syrah } \\
(\mathrm{mg} / \mathrm{kg})\end{array}$ & $\begin{array}{l}\text { Nero } \\
\text { d'Avola } \\
(\mathrm{mg} / \mathrm{kg})\end{array}$ \\
\hline \multicolumn{4}{|l|}{ Flavonoids } \\
\hline Quercetin & 178.60 & 170.23 & 51.34 \\
\hline $\begin{array}{l}\text { Quercetin-3-O- } \\
\text { glucuronide }\end{array}$ & 76.36 & 33.83 & 63.89 \\
\hline $\begin{array}{l}\text { Quercetin-3-O- } \\
\text { galactoside }\end{array}$ & 50.04 & 39.35 & 31.08 \\
\hline Eriodictyol & 22.60 & 21.01 & / \\
\hline Kaempferol & 43.54 & 34.04 & 22.05 \\
\hline $\begin{array}{l}\text { Kaempferol-7- } O \text { - } \\
\text { glucuronide }\end{array}$ & 23.01 & 10.40 & 21.90 \\
\hline $\begin{array}{l}\text { Kaempferol-3-O- } \\
\text { glucoside }\end{array}$ & 29.27 & 26.26 & 25.11 \\
\hline Myricetin & 22.89 & 21.13 & 22.42 \\
\hline $\begin{array}{l}\text { Myricetin-3-O- } \\
\text { glucoside }\end{array}$ & 31.50 & 26.14 & 24.90 \\
\hline Naringenin & 30.51 & 30.65 & 30.48 \\
\hline Hesperidin & 22.87 & 23.06 & 20.34 \\
\hline Procyanidin B2 & 52.48 & 34.14 & 25.01 \\
\hline $\begin{array}{l}\text { Epicatechin-3-O- } \\
\text { vanillate }\end{array}$ & 23.53 & 11.17 & 10.55 \\
\hline \multicolumn{4}{|l|}{ Phenols } \\
\hline Resveratrol & 32.65 & 8.80 & 9.22 \\
\hline Resveratrol dimer & 13.34 & I & 9.56 \\
\hline Resveratrol trimer & 11.30 & 9.87 & 13.05 \\
\hline $\begin{array}{l}\text { Resveratrol } \\
\text { tetramer }\end{array}$ & 16.20 & I & 10.22 \\
\hline $\begin{array}{l}p \text {-Hydroxybenzoic } \\
\text { acid }\end{array}$ & 9.78 & 9.57 & 15.56 \\
\hline p-Coumaric acid & 13.63 & 18.46 & 12.87 \\
\hline $\begin{array}{l}\text { Gallic acid ethyl } \\
\text { ester }\end{array}$ & 434.95 & 344.22 & 155.61 \\
\hline Caffeic acid & 15.78 & 25.30 & 12.87 \\
\hline Gallic acid & 518.47 & 277.84 & 151.58 \\
\hline Syringic acid & 350.32 & 270.85 & 122.49 \\
\hline \multicolumn{4}{|l|}{ Anthocyanins } \\
\hline $\begin{array}{l}\text { Cyanidin-3-O- } \\
\text { glucoside }\end{array}$ & 24.49 & 23.11 & 28.63 \\
\hline
\end{tabular}

Myricetin (and its glycoside myricetin-3-O-glucoside) was also found in approximately $50 \mathrm{mg} / \mathrm{kg}$ amount in each cultivar extract. Again, the flavonoid exhibits an ample spectrum of physiological (antioxidant, anticancer, antidiabetic and antiinflammatory and neuroprotective) activities. ${ }^{22}$ Numerous studies have suggested that the compound may be beneficial to protect against diseases such as Parkinson's and Alzheimer's. ${ }^{23}$

In brief, likewise to red-wine, polyphenols are a complex mixture of flavonoids (mainly anthocyanins and flavan-3-ols) and non-flavonoids (such as resveratrol and gallic acid) with oligomeric and polymeric procyanidins often representing 25$50 \%$ of the total phenolic constituents. ${ }^{24}$ Contrary to red wine, however, in the wine pomace aqueous extracts sustainably 
sourced via microwave hydrodiffusion and gravity, flavanols and procyanidins are not the most abundant biophenols.

Procyanidin B2, the most widely distributed natural procyanidin, is abundant $(52 \mathrm{mg} / \mathrm{kg})$ in the Perricone extract and still substantially present $(25 \mathrm{mg} / \mathrm{kg})$ in the Nero d'Avola extract $(24 \mathrm{mg} / \mathrm{kg}$ in the Syrah extract). The molecule was recently found to mitigate glucose-induced reticulum stress in endothelium implicated in the pathophysiology of diabetes and its vascular complications..$^{25}$

Finally, naringenin, at approximately $30 \mathrm{mg} / \mathrm{kg}$ and hesperidin at about $21 \mathrm{mg} / \mathrm{kg}$ are present in almost equal amounts in all three cultivar extracts. Both known amid red wine polyphenols, ${ }^{26}$ the former flavonone and the latter flavanone glycoside have wide-scope physiological activities, including broad-scope antiviral activity. ${ }^{27,28}$

\section{Conclusions}

Originally introduced by Chemat, Visinoni and co-workers in 2008 for the extraction of essential oils without adding any solvent or water, ${ }^{29}$ microwave hydrodiffusion and gravity has been successfully applied to extract valued bioproducts to the pomace of numerous fruits, including bilberry, ${ }^{30}$ citrus, ${ }^{31}$ and apple. ${ }^{32}$ The first application to the solvent-free extraction of grape pressing by-products was reported by Chemat and coworkers in 2013. ${ }^{33}$ The team added the MHG extract to the grape juice obtained in the laboratory along with the grape pomace. The resulting fortified grape juice had significantly higher total phenolics content, was redder and less sweet in comparison to the natural grape juice. ${ }^{33}$

In this work, MHG has been applied to different industrial wine pomaces after soaking the pomace in water in order to study the $i$ ) phenolic profile from different red grape cultivars grown in Sicily, and ii) the stability of the red biophenol-rich extracts thereby obtained. The lack of chemical stability of anthocyanins in the presence of air's oxygen and thus during food processing, storage, and commercialization, is the main issue that limits the widespread uptake of these colorant molecules in the food industry. Quick oxidation occurs, and the red color is converted in undesirable brown, a color particularly disliked by food and beverage consumers. ${ }^{34}$ Several stabilization methods have been developed, including additions of co-pigments, phenolic compounds, metals, and exclusion of $\mathrm{O}_{2}$ during processing and storage. ${ }^{35}$

Now, we show evidence that the MHG aqueous extract of red wine pomace is so stable that it can be safely handled in open atmosphere, stored in freezer for over one year (15 months), lyophilized for several days and eventually analyzed without alteration of its deep red-violet color, while retaining exceptionally high content of phenolic compounds. Likewise to what observed with Opuntia-ficus indica red betalains obtained from the fruit peel via $\mathrm{MHG},{ }^{36}$ stabilization against oxidative degradation is due to the concomitant extraction of numerous strongly antioxidant water-soluble biophenols.

These findings provide a simple and economically viable extraction route to anthocyanin-based red extracts that can be used as food colorants as well as to formulate nutraceutical, cosmetic and personal care products starting from an agricultural by-product annually produced in $>10$ million tonne amount.

Finally, it also of relevance to this report that in scaled-up MHG extraction of phenolics from fruit, the cost of manufacturing largely depends on the cost of raw material
$(81.09 \%)$, followed by the cost of utilities $(13.09 \%) .{ }^{37}$ Since the cost of wine pomace is extremely low, MHG is particularly well suited for the valorization of red wine pomace also from the practical application viewpoint.

Given the large amounts of bioactive compounds, it is anticipated that these red wine pomace extracts may have significant physiological activity, especially those originating from the Perricone and Syrah cultivars. The outcomes of biological experiments carried out using these extracts will be reported in due course.

\section{Author Information \\ Corresponding Authors \\ *E-mail: rosaria.ciriminna@cnr.it \\ *E-mail: beppe.avellone@unipa.it \\ ORCIID}

Marzia Sciortino: 0000-0002-2805-4452

Giuseppe Avellone: 0000-0002-4539-6059

Antonino Scurria: 0000-0001-5624-6833

Luca Bertoli: 0000-0002-4333-0080

Diego Carnaroglio: 0000-0002-8311-7233

David Bongiorno: 0000-0002-9856-356X

Mario Pagliaro: 0000-0002-5096-329X

Rosaria Ciriminna: 0000-0001-6596-1572

Notes

The authors declare the following competing financial interest(s): Milestone manufactures extractors for microwaveassisted extraction of natural products.

\section{Acknowledgements}

This study is dedicated to the memory of Don Antonino Scavuzzo, for all he has done for his students including one of us (M.P.). We thank Dr Francesco Lo Sicco and Aziende Agricole Biologiche Tamburello (Monreale, Italy) for the generous gift of wine pomace samples.

\section{References}

1. C.M. Galanakis (Ed.), Handbook of Grape Processing ByProducts, Academic Press, Cambridge (MA): 2017.

2. C. Beres, G.N. Costa, I. Cabezudo, N.K. da Silva-James, A.S. Teles, A.P. Cruz, C. Mellinger-Silva, R.V. Tonon, L.M. Cabral, S.P. Freitas, Towards integral utilization of grape pomace from winemaking process: A review, Waste Manag. 2017, 68 581-594. https://doi.org/10.1016/j.wasman.2017.07.017

3. C.M. Peixoto , M.I. Dias, M.J. Alves, R.C. Calhelha, L. Barros, S.P. Pinho, I.C.F.R. Ferreira, Grape pomace as a source of phenolic compounds and diverse bioactive properties, Food Chem. 2018, 253, 132-138. https://doi.org/10.1016/j.foodchem.2018.01.163

4. Market Study Report, Global Resveratrol Market 2020 by Manufacturers, Regions, Type and Application, Forecast to 2025, Selbyville, (DE): 2020.

5. R. G. Maroun, H. N. Rajha, E. Vorobiev, N. Louka, Emerging Technologies for the Recovery of Valuable Compounds From Grape Processing By-Products, In Handbook of Grape Processing By-Products, C.M. Galanakis 
(Ed.), Academic Press, Cambridge (MA): 2017; pp.155-181. https://doi.org/10.1016/B978-0-12-809870-7.00007-7

6. R. Ciriminna, D. Carnaroglio, R. Delisi, S. Arvati, A. Tamburino, M. Pagliaro, Industrial Feasibility of Natural Products Extraction with Microwave Technology, $\begin{array}{llll}\text { ChemistrySelect } & \mathbf{2 0 1 6}, & 1,\end{array}$ http://dx.doi.org/10.1002/slct.20160007

7. N. Ćurko, K. Kovačević Ganić, M. Tomašević, L. Gracin, Microwave-assisted extraction of polyphenolic compounds from grape skin pomace, The application of innovative technologies in bioactive compounds isolation from organic waste in the wine production, Zagreb, 26 January 2016. http://bioactive-winewaste.com/wpcontent/uploads/2016/02/Curko.pdf

8. N. Ćurko, K. Kelšin, V. Dragović-Uzelac, D. Valinger, M. Tomašević, K. Kovačević Ganić, Microwave-assisted extraction of different groups of phenolic compounds from grape skin pomaces: modeling and optimization, Pol. J. Food $\begin{array}{llll}\text { Nutr. } & \text { Sci. } & \text { 2019, } & \text { 69, }\end{array}$ https://doi.org/10.31883/pjfns/109423

9. EFSA Panel on Food Additives and Nutrient Sources added to Food, Scientific Opinion on the re-evaluation of anthocyanins (E 163) as a food additive, EFSA J. 2013, 11, 3145. https://doi.org/10.2903/j.efsa.2013.3145

10. J. García-Lomillo, M.L. González-SanJosé, Applications of Wine Pomace in the Food Industry: Approaches and Functions, Compr. Rev. Food Sci. Food Saf. 2017, 16, 3-22. https://doi.org/10.1111/1541-4337.12238

11. G. Mazza, F. J. Francis, Anthocyanins in grapes and grape products, Crit. Rev. Food Sci. Nutr. 1995, 35, 341-371, https://doi.org/10.1080/10408399509527704

12. Acumen Research and Consulting, Anthocyanin Market (By Product: Cyanidin, Delphinidin, Malvidin, Pelargonidin, Peonidin, Petunidin; By End Use: Animal Feed, Cosmetics \& Personal Care, Food \& Beverage Industry, Nutraceutical Industry, Pharmaceutical Industry; By Source: Cereals, Flowers, Fruits, Legumes, Vegetables) - Global Industry Analysis, Market Size, Opportunities and Forecast, 2019 2026, Pashan (India): 2019.

13. T. Gervasi, F. Oliveri, V. Gottuso, M. Squadrito, G. Bartolomeo, N. Cicero, G. Dugo, Nero d'Avola and Perricone cultivars: determination of polyphenols, flavonoids and anthocyanins in grapes and wines, Nat. Prod. Res. 2016, 30, 2329-2337. https://doi.org/10.1080/14786419.2016.1174229

14. G. A. Logan, G. S. Howell, M. G. Nair, Cyanidin-3-oglucoside is an important anthocyanin in several clones of vitis vinifera $\mathrm{L}$. pinot noir fruits and resulting wine from Michigan and New Zealand, Internet J. Enol. Vitic. 2009, 5 (2), 1-12. https://www.infowine.com/intranet/libretti/libretto7020-011.pdf

15. I. I. Rockenbach, E. Rodrigues, L. V. Gonzaga, V. Caliari, M. I. Genovese, A. E. de Souza Schmidt Gonçalves, R. Fett, Phenolic compounds content and antioxidant activity in pomace from selected red grapes (Vitis vinifera L. and Vitis labrusca L.) widely produced in Brazil, Food Chem. 2011, 127, 174-179. https://doi.org/10.1016/j.foodchem.2010.12.137

16. Y. Yilmaz, R.T. Toledo, Major flavonoids in grape seeds and skins: Antioxidant capacity of catechin, epicatechin, and gallic acid, J. Agr. Food Chem. 2004, 52, 255-260.

17. The Australian Wine Research Institute, Identification of the major drivers of 'phenolic' taste in white wines, Adelaide: 2012.

https://www.wineaustralia.com/research/projects/identification -of-the-major-drivers-of-\%E2\%80\%98

18. M. Careri, C. Corradini, L. Elviri, I. Nicoletti, I. Zagnoni, Direct HPLC Analysis of Quercetin and trans-Resveratrol in
Red Wine, Grape, and Winemaking Byproducts, J. Agr. Food Chem. 2003, 51, 5226-5231. https://doi.org/10.1021/jf034149g

19. V. Amico, R. Chillemi, S. Mangiafico, C. Spatafora, C. Tringali, Polyphenol-enriched fractions from Sicilian grape pomace: HPLC-DAD analysis and antioxidant activity, Biores. Technol. 2008, 99, 5960-5966. https://doi.org/10.1016/j.biortech.2007.10.037

20. W. Wang, C. Sun, L. Mao, P. Ma, F. Liu, J. Yang, Y. Gao, The biological activities, chemical stability, metabolism and delivery systems of quercetin: A review, Tr. Food Sci. Technol. 2016, 56, 21-38, https://doi.org/10.1016/j.tifs.2016.07.004

21. D. Kumar Semwal, R. Badoni Semwal, S. Combrinck, A. Viljoen, Myricetin: A Dietary Molecule with Diverse Biological Activities, Nutrients 2016, 8, 90. https://doi.org/10.3390/nu8020090

22. D. Kashyap, A. Sharma, H. S. Tuli, K. Sak, S. Punia, T. K. Mukherjee, Kaempferol - A dietary anticancer molecule with multiple mechanisms of action: Recent trends and advancements, J. Funct. Foods 201, 30, 203-219. https://dx.doi.org/ 10.1016/j.jff.2017.01.022

23. M. Liu, H. Guo, Z. Li, C. Zhang, X. Zhang, Q. Cui, J. Tian, Molecular Level Insight Into the Benefit of Myricetin and Dihydromyricetin Uptake in Patients With Alzheimer's Diseases, Front. Aging Neurosci. 2020, 12, 601603. https://doi.org/10.3389/fnagi.2020.601603

24. A.L. Waterhouse, Wine Phenolics, Ann. N. Y. Acad. Sci. 2002, 957, 21-36. https://doi.org/10.1111/j.17496632.2002.tb02903.x

25. X. Nie, W. Tang, Z. Zhang, C. Yang, L. Qian, X. Xie, E. Qiang, J. Zhao, W. Zhao, L. Xiao, N. Wang, Procyanidin B2 mitigates endothelial endoplasmic reticulum stress through a PPAR $\delta$-Dependent mechanism, Redox Biol. 2020, 37, 101728, https://doi.org/10.1016/j.redox.2020.101728

26. I. Baranowska, S. Magiera, Development and validation of a UHPLC method for the determination of flavonoids in red wine, J. AOAC Int. 2011, 94, 786-794.

27. R. Kumer Saha, T. Takahashi, T. Suzuki, Glucosyl hesperidin prevents influenza a virus replication in vitro by inhibition of viral sialidase, Biol. Pharm. Bull. 2009, 32, 11881192. https://doi.org/10.1248/bpb.32.1188

28. A. H. Depieri Cataneo, D. Kuczera, A. C. Koishi, C. Zanluca, G. Ferreira Silveira, T. Bonato de Arruda, A. Akemi Suzukawa, L. Oliveira Bortot, M. Dias-Baruffi, W. Aparecido Verri Jr., A. Waloski Robert, M. A. Stimamiglio, C. Nunes Duarte dos Santos, P. Fanini Wowk, J. Bordignon, The citrus flavonoid naringenin impairs the in vitro infection of human cells by Zika virus, Sci. Rep. 2019, 9, 16348. https://doi.org/10.1038/s41598-019-52626-3

29. M. Abert Vian, X. Fernandez, F. Visinoni, F. Chemat, Microwave hydrodiffusion and gravity, a new technique for extraction of essential oils, J. Chromatogr. A 2008, 1190, 1417. https://doi.org/10.1016/j.chroma.2008.02.086

30. H. Karthikeyan Ravi, C. Breil, M. Abert Vian, F. Chemat, P. Rimantas Venskutonis, Biorefining of Bilberry (Vaccinium myrtillus L.) Pomace Using Microwave Hydrodiffusion and Gravity, ACS Sustainable Chem. Eng. 2018 , 6 , 4185-4193. https://doi.org/10.1021/acssuschemeng.7b04592

31. R. Ciriminna, A. Fidalgo, D. Carnaroglio, G. Cravotto, G. Grillo, A. Tamburino, L. M. Ilharco, M. Pagliaro, EcoFriendly Extraction of Pectin and Essential Oils from Orange and Lemon Peels, ACS Sustainable Chem. Eng. 2016, 4, 22432251. http://dx.doi.org/10.1021/acssuschemeng.5b01716

32. C. P. Passos, J. Calvão, S. Ferreira, R. Jorge, P.A.R. Fernandes, V.M.R. Martins, E. Coelho, D.F. Wessel, S.M. 
Cardoso, C. Nunes, M.A. Coimbra, Microwave hydrodiffusion and gravity: an emergent technology for green extraction of non-volatile compounds, MicroBioTec 2015 - Congress of microbiology and biotechnology, Évora (Portugal), 10-12 December 2015. http://hdl.handle.net/10198/16611

33. S. Al Bittar, S. Périno-Issartier, O. Dangles, F. Chemat, An innovative grape juice enriched in polyphenols by microwave-assisted extraction, Food Chem. 2013, 141, 32683272. http://dx.doi.org/10.1016/j.foodchem.2013.05.134

34. D.A. Zellner, P Paula Durlach, Effect of Color on Expected and Experienced Refreshment, Intensity, and Liking of Beverages, Am. J. Psychol. 2003, 116, 633-647. https://doi.org/10.2307/1423663

35. R. Cortez, D.A. Luna-Vital, D. Margulis, E. Gonzalez de Mejia, Natural Pigments: Stabilization Methods of Anthocyanins for Food Applications, Compr. Rev. Food Sci. Food Saf. 2017, 16, 180-198. https://doi.org/10.1111/15414337.12244

36. R. Ciriminna, A. M. Fidalgo, G. Avellone, C. Danzì, G. Timpanaro, M. Locatelli, D. Carnaroglio, F. Meneguzzo, L. M. Ilharco, M. Pagliaro, Integral extraction of Opuntia ficusindica peel bioproducts via microwave-assisted hydrodiffusion and hydrodistillation, ACS Sustainable Chem. Eng. 2019, 7, 7884-7891. https://doi.org/10.1021/acssuschemeng.9b00502

37. D.P. Moraes, M.L. Machado, C.A.A. Farias, J. S. Barin, G. L. Zabot, J. Lozano-Sánchez, D. F. Ferreira, M.a Vizzotto, F. J. Leyva-Jimenez, T. L. Da Silveira, E. F. Ries, M. T. Barcia, Effect of Microwave Hydrodiffusion and Gravity on the Extraction of Phenolic Compounds and Antioxidant Properties of Blackberries (Rubus spp.): Scale-Up Extraction, Food Biopr. Technol. 2020, 13, 2200-2216. https://doi.org/10.1007/s11947-020-02557-Z 